\title{
Does Donor Liver Extraction Time Affect Early Allograft Function in Deceased Adult Liver Transplant Recipients? is
}

\author{
Mohamed Ghazaly ${ }^{1,2^{*}}$, Veena Surendrakumar ${ }^{1}$, Navneet Tiwari ${ }^{1}$, Pulkit Sethi ${ }^{1}$
}

'Department of Transplant Surgery, Addenbrookes Hospital, Cambridge, United Kingdom 2Department of Surgery, Tanta University, Tanta, Gharbia, Egypt

\section{ABSTRACT}

Background: Recent work has identified time taken to remove a donor liver during organ retrieval (the extraction time) as a previously unrecognized variable affecting transplant outcome. We evaluated the effect of extraction time on early graft function in our own practice in a busy liver centre.

Patients and Methods: 218 recipients of liver grafts transplanted at our centre (Addenbrooke's, Cambridge) between October 2014 and October 2017 were evaluated. Early graft function was assessed by model for early allograft function (MEAF) score in both univariate and multivariate analysis including other variables known to affect outcome such as cold ischaemia time (CIT), warm ischaemia time (WIT), operative time, and terminal donor sodium concentration.

Results: In univariate analysis, extraction time, and CIT had a significant independent effect on MEAF score $(P=0.041,0.008)$. Both prolonged donor extraction time and CIT were independently associated with a significant increase in the MEAF score in multivariate analysis $\{(95 \%$ confidence interval, $0.136-0.563 ; P=0.044)$, (95\% confidence interval, $0.239-0.761 ; \mathrm{P}=0.011)\}$.

Conclusion: Donor liver extraction time has an independent effect on early graft function in deceased donor liver transplantation. Shortening donor extraction time during liver procurement could decrease the incidence of early allograft dysfunction.

Key words: donor hepatectomy timings, early allograft dysfunction, extraction time, liver transplantation, transplant outcome.

\section{INTRODUCTION}

The disparity between donor numbers and patients on the OLT waiting list has led transplant units to expand the criteria for donor liver allograft acceptance to include donation after circulatory death (DCD) and older age of donors, increasing the chance of unfavourable consequences (1). Ischemic injury, particularly warm ischaemic injury, which is inevitable during liver procurement and subsequent implantation, increases the risk of primary nonfunction, early allograft dysfunction, and affects overall graft and patient survival $(2,3,4)$.
*Corresponding author: Mohamed Ghazaly M.Sc MD Transplant Surgery UCL (University College London) Lecturer and Consultant of Oncological/HPB Surgery Faculty of Medicine

Department of Surgery, Tanta University Hospitals, El-Gaish, Tanta Qism 2, Tanta, Gharbia Governorate, Egypt Tel: +2 01112137427

E-mail: mohamed.ghazaly@med.tanta.edu.eg mohamed.ghazaly@nhs.net

'sThe Abstract has been presented at 19th Congress of The European Society for Organ Transplantation (ESOT) Copenhagen, Denmark, 15-18 September 2019.

\section{Abbreviations:}

AlH: Auto-immune Hepatitis.

ALF: Acute Liver Failure.

ALT: Alanine Aminotransferase.

ArLD: Alcohol related Liver Disease.

BMl: Body Mass Index.

CIT: Cold Ischemia Time.

CKD: Chronic Kidney Disease.

DBD: Donation after Brain stem Death.

DCD: Donation after Circulatory Death.

EAD: Early Allograft Dysfunction.

HCC: Hepatocellular Carcinoma.

ICU: Intensive Care Unit.

INR: International Normalised Ratio.

MEAF: Model of Early Allograft Function.

PNF: Primary Non-Function.

PT: Prothrombin Time.

PVT: Portal Vein Thrombosis.

UKELD: United Kingdom End Stage

Liver Disease.

WIT: Warm Ischemia Time.

Received: 23.10 .2020

Accepted: 10.12.2020

Copyright (1) Celsius Publishing House www.sgo-iasgo.com 
Early Allograft Dysfunction (EAD) as defined by the Olthoff criteria is the presence of one of the following; bilirubin $>170 \mu \mathrm{mol} / \mathrm{L}$ on postoperative day (POD) 7 ; International normalized ratio (INR) $>1.6$ on POD 7; or ALT > $2000 \mathrm{IU} / \mathrm{mL}$ from day 1 to day 7 following transplantation (5). EAD is a dichotomous variable available seven days after transplantation, which does not allow the severity of the dysfunction to be graded. $E A D$ is either present or it is not (6). The Model of Early Allograft Function (MEAF) has recently been suggested as an alternate method of categorizing early graft dysfunction after liver transplantation in such a continuous score and is dependent on bilirubin, international normalized ratio, and alanine aminotransferase within the first 3 postoperative days (7).

MEAF score (model of early allograft function) quantifies early graft function between 0 and 10 on a scale. It is calculated based on peak ALT and INR on days 1 to 3 , and the bilirubin concentration on the third postoperative day $(7,8)$. It has been previously validated as a patient and graft survival indicator after liver transplantation $(6,7)$. A one-point rise in MEAF raises the hazard ratio $(H R)$ for patient mortality at 3,6 , and 12 months after liver transplantation $(6,7)$. While it is unlikely that any score dependent on only a few variables would ever be a perfect indicator of (longterm) outcome, its continuity is a major benefit of the MEAF score (6).

Cold storage relies upon the fact that metabolism decreases with decreasing temperature (9). In situ cold perfusion during liver procurement and before organ goes into ice on the back-table cools the liver slowly, and its temperature does not reach $4 \mathrm{C}$ before extraction from the donor's body $(10,11)$. Longer donor extraction time was associated with an increased incidence of delayed graft function in kidney transplantation (12). Only twice in the literature was the correlation between donor extraction time and early graft function after deceased donor liver transplantation examined $(6,8)$.

The aim of our study is to evaluate the impact of donor extraction time as a possible independent modifiable variable among other timings (cold and warm ischemia times) on liver transplant outcome with special emphasis on early graft function (using both the EAD definition and MEAF score).

\section{PATIENTS AND METHODS}

257 adult liver transplant recipients from $1^{\text {st }}$ October 2014 till $1^{\text {st }}$ October 2017, at our Centre (Addenbrooke's hospital, Cambridge University Hospital) were included.
Sixteen patients were re-transplanted, two retransplanted twice (18 re-transplants) making 275 transplants in total. 39 grafts which had either ex situ machine perfusion or in situ normothermic regional perfusion (NRP) were excluded, and there were inadequate data for 18 patients making the final number of 218 transplants.

We examined the impact of donor liver extraction time on early graft function in 218 recipients of grafts harvested by different centres both locally and nationally but transplanted at our center. Donor extraction time was defined as time elapsed from donor aortic cross clamping to removal of the liver into an ice bowl on the back table. These times were recorded contemporaneously but accessed retrospectively for the study. The remaining data were prospectively recorded in the recipient's electronic patient record (EPIC systems, Madison, WI, USA).

The following donor data were analyzed: donor age, height, weight, body mass index (BMI), serum sodium concentration, cold ischaemia time (CIT), secondary anastomotic warm ischaemia time (WIT), and type of graft; whether donation after brain-stem death (DBD) or donation after circulatory death (DCD). Recipient demographic data, date of transplantation and re-transplantation, age, HCC incidence, primary liver disease, operative time, and potential risk factors including dialysis, inotropes, and mechanical ventilation.

The outcome of transplant was assessed clinically and biochemically; days $1,3,5$ and 7 post-transplant ALT, Bilirubin, prothrombin (PT) values/calculated INR and creatinine. The incidence of early allograft dysfunction (Olthoff criteria, EAD) (5), primary non function (PNF), Model of Early Allograft function (MEAF) (7), the length of hospitalisation, length of ICU stay, incidence of acute rejection within the first year and 30 days and one year patient mortality.

Early graft function was evaluated by using both EAD (Early Allograft Dysfunction) as defined by the Olthoff criteria (5) and MEAF score (model of early allograft function) which allows to quantify early graft function, is calculated based on ALT, INR and bilirubin levels $(7,8)$. PNF was defined as graft loss, re-transplantation or patient death within 14 days of initial transplant not a consequence of hepatic artery thrombosis, biliary complication, recurrent disease or acute rejection. Early graft function was assessed by the model for early allograft function (MEAF) score in both univariate and multivariable models involving donor extraction time, cold ischemia time (CIT), warm ischemia time (WIT), operative time, and last donor sodium available. The degree of tissue dissection which took place before 
organ cooling versus after organ cooling varied depending on the donor body habitus, donor type (DBD vs DCD), anatomy, and procuring team, resulting in a variable extraction time.

This study was carried out as a service evaluation to evaluate the incidence of PNF in our practice.

\section{Statistical analysis}

The continuous data summary is stated median and interquartile range (IQR). The numbers and percentages of categorical data are stated. With SPSS statistical software (IBM ${ }^{\circledR}$, SPSS ${ }^{\circledR}$ Statistics 20 , Chicago, IL, USA), statistical analysis was performed. For normally distributed data, the Student $T$ test was used. The Mann-Whitney $U$ test was used for non-normally distributed data. The link between MEAF score and these variables (donor extraction time, CIT, WIT, Operative time and donor serum sodium) was assessed using univariate and multivariable linear regression analyses. Statistical significance was indicated by $P$ values of less than 0.05 .

\section{RESULTS}

Eighteen patients whose data was missing, and 39 grafts which had either ex situ machine perfusion or in situ normothermic regional perfusion (NRP) were excluded leaving 218 adult liver transplant recipients in the study. Donor and graft variables including ischaemia times and type of graft are provided in table 1. Median donor extraction time was 33 minutes (IQR 12-67 minutes) (fig. 1). DCD livers were more influenced by extraction times by having longer donor

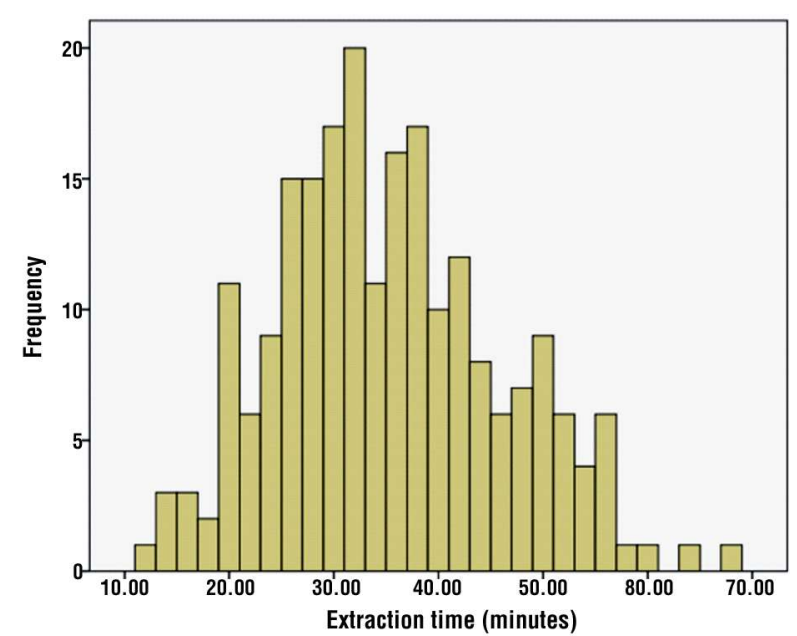

Figure 1 - Liver Extraction time; Histogram of liver extraction times in minutes

hepatectomy times than DBD livers [median 41 minutes (IRQ 17 to 63) vs 32 minutes (IQR12 to 67), P <001].

Recipients characteristics are summarised in table 2 , including age, HCC incidence, primary liver disease, and potential risk factors including recipient pre-transplant dialysis, use of inotropes and mechanical ventilation. Posttransplant liver and kidney function tests (table 3), and post-transplant outcome parameters are given in table 4, including; length of intensive care unit (ICU) and hospital stay, and mortality. The median Model of Early Allograft function (MEAF) score was 4.82 (3.61 - 6.51), with $5 \%$ one-year mortality.

We observed a significant correlation between donor extraction time and MEAF score in the univariate analysis $(\mathrm{P}=0.041)$. There was also a strong correlation between Cold Ischemia Time with the MEAF score

Table 1 - Donor and Graft Characteristics

\begin{tabular}{|c|c|c|c|}
\hline Donor Variables & $\begin{array}{r}\text { Extraction time } \\
<45 \text { min } \\
\text { (n. 179) }\end{array}$ & $\begin{array}{r}\text { Extraction time } \\
>45 \text { min } \\
\text { (n. 39) }\end{array}$ & $\begin{array}{l}\text { Total } \\
\text { (218) } \\
\end{array}$ \\
\hline Age (Years) Median (range) & $52(39-61)$ & $48(35-53)$ & $50(39-60)$ \\
\hline Height $(\mathrm{cm})$ Median (range) & $173(165-179)$ & $173(163-178)$ & $173(165-179)$ \\
\hline Weight (kg) Median (range) & $80(68-89)$ & $80(70-90)$ & $80(68-90)$ \\
\hline $\mathrm{BMI}\left(\mathrm{Kg} / \mathrm{m}^{2}\right)$ Median (range) & $26(23-30)$ & $27(25-29)$ & $26(23-30)$ \\
\hline $\mathrm{Na}(\mathrm{mmol} / \mathrm{L})$ Median (range) & $149(142-153)$ & $148(143-153)$ & $148(143-153)$ \\
\hline Cold Ischemia Time CIT (min) Median (range) & $512(417-635)$ & $482(384-640)$ & $505(411-635)$ \\
\hline Warm (Anastmotic) Ischemia Time WIT (min) Median (range) & $45(37-51)$ & $41(35-49)$ & $45(37-51)$ \\
\hline Operative Time (min) Median (range) & $434(380-500)$ & $406(360-480)$ & $430(380-500)$ \\
\hline Type of Graft DBD Donor (\%) & $141(78.8 \%)$ & $30(76.9 \%)$ & $171(78.4 \%)$ \\
\hline DCD Donor (\%) & $38(21.2 \%)$ & $9(23.1 \%)$ & $47(21.6 \%)$ \\
\hline
\end{tabular}

Data are median (IQR) or $\mathrm{n}(\%)$. 
Table 2 - Recipients characteristics

\begin{tabular}{|c|c|c|c|}
\hline $\begin{array}{l}\text { Variables } \\
\text { (n. 179) }\end{array}$ & $\begin{array}{r}\text { Extraction time }<45 \text { min } \\
(\text { (n. 39) }\end{array}$ & $\begin{array}{r}\text { Extraction time }>45 \min \\
(218)\end{array}$ & Total \\
\hline $\begin{array}{c}\text { Number } \\
\text { Age }\end{array}$ & $\begin{array}{r}179 \\
56(46-62)\end{array}$ & $\begin{array}{r}39 \\
54(44-63)\end{array}$ & $\begin{array}{r}218 \\
56(45-62)\end{array}$ \\
\hline \multicolumn{4}{|l|}{ Aetiology } \\
\hline Viral & $19(10.6 \%)$ & $5(12.8 \%)$ & $24(11 \%)$ \\
\hline ALD & $36(20.1 \%)$ & $9(23 \%)$ & $45(20.6 \%)$ \\
\hline NASH & $4(2.2 \%)$ & $1(2.6 \%)$ & 5 (2.3\%) \\
\hline PSC & $25(14 \%)$ & $9(23 \%)$ & $34(15.6 \%)$ \\
\hline PBC & $17(9.5 \%)$ & $3(7.7 \%)$ & $20(9.2 \%)$ \\
\hline AlH/Cholestasis & $4(2.2 \%)$ & 0 & $4(1.8 \%)$ \\
\hline Acute Liver Failure (ALF) & $6(3.3 \%)$ & $2(5.1 \%)$ & $8(3.7 \%)$ \\
\hline Other & & & 78 \\
\hline $\mathrm{HCC}$ & $24(13.4 \%)$ & $8(20.5 \%)$ & $32(14.7 \%)$ \\
\hline \multicolumn{4}{|l|}{ Risk Factors } \\
\hline PreTx Dialysis/CKD & $23(13 \%)$ & $5(12.8 \%)$ & $28(13 \%)$ \\
\hline PreTx Inotropes & $15(8.5 \%)$ & $5(12.8 \%)$ & $20(9.3 \%)$ \\
\hline PreTx Mechanical Ventilation & $15(8.5 \%)$ & $5(12.8 \%)$ & $20(9.3 \%)$ \\
\hline
\end{tabular}

Data are median (IQR) or $n(\%)$

Table 3 - Post Transplant Liver Function Tests

\begin{tabular}{|c|c|c|c|}
\hline Variables & $\begin{array}{r}\text { Extraction time }<45 \mathrm{~min} \\
(\text { (n. 179) }\end{array}$ & $\begin{array}{r}\text { Extraction time }>45 \text { min } \\
(\text { (n. 39) }\end{array}$ & $\begin{array}{l}\text { Total } \\
\text { (218) }\end{array}$ \\
\hline Lactate Day $1^{*}$ & $1.2(1-1.5)$ & $1.2(1.1-1.7)$ & $1.2(1.02-1.50)$ \\
\hline ALT (u/l) Day 1 & $302(84-707)$ & $338(123-735)$ & $312(90-708)$ \\
\hline Bilirubin (umol/l) Day 1 & $58(32-97)$ & $52(31-90)$ & $56(32-95)$ \\
\hline PT (sec) Day 1 & $23.3(17.6-54)$ & $24.3(17.8-65)$ & $23.8(17.6-54.8)$ \\
\hline Creatinine Day 1 & $97(73-126)$ & $106(81-162)$ & $99(74-134)$ \\
\hline ALT (u/l) Day 3 & $368(206-623)$ & $427(255-762)$ & $399(208-677)$ \\
\hline Bilirubin (umol/l) Day 3 & $48(27-91)$ & $46(20-123)$ & $47(26-97)$ \\
\hline PT (sec) Day 3 & $12.6(2-14.9)$ & $12.4(2.4-14.7)$ & $12.6(2.2-14.9)$ \\
\hline Creatinine Day 3 & $86(62-133)$ & $94(69-141)$ & $88(62-134)$ \\
\hline ALT (u/l)Day 5 & $204(141-353)$ & $267(168-450)$ & $221(150-389)$ \\
\hline Bilirubin (umol/l) Day 5 & $48(25-100)$ & $61(24-153)$ & $52(26-106)$ \\
\hline PT (sec) Day 5 & $12.2(1.3-14.4)$ & $12.1(1.6-14.5)$ & $12.2(1.4-14.4)$ \\
\hline Creatinine Day 5 & $73(53-107)$ & $71(57-121)$ & $73(54-110)$ \\
\hline ALT (u/l) Day 7 & $155(99-235)$ & $196(132-290)$ & $160(102-251)$ \\
\hline Bilirubin (umol/l) Day 7 & $38(24-81)$ & $54(30-159)$ & $40(26-84)$ \\
\hline PT (sec) Day 7 & $12(1.3-13.7)$ & $12.4(1.2-13.3)$ & $12.1(1.3-13.7)$ \\
\hline Creatinine Day 7 & $65(49-92)$ & $71(56-110)$ & $65(50-93)$ \\
\hline
\end{tabular}

Data are median (IQR).

*Lactate levels (Day 1) were obtained 24 hours after reperfusion.

$(P=0.008)$. A substantial increase in the MEAF score $(P=0.044)$ was still correlated with extended donor extraction time in the multivariate regression model $(P=0.044)$ (tables 5, 6 and fig. 2). In addition, there was also still a significant correlation between $\mathrm{CIT}$ and the MEAF score $(P=0.011)$.

\section{DISCUSSION}

In the early postoperative period, most transplanted patients have a certain degree of graft dysfunction, ranging from a mild degree of reversible organ dysfunction to a serious and non-reversible dysfunction known as primary graft non-function (5). The overall incidence 
Table 4 - Post transplant outcome

\begin{tabular}{lr}
\hline Variables & Total \\
\hline Early Allograft Dysfunction EAD (\%) & $37(17 \%)$ \\
\hline Model of Early Allograft function MEAF Score & $4.82(3.61-6.51)$ \\
\hline Primary Non-function PNF (\%) & $3(1.4 \%)$ \\
\hdashline Rejection (\%) & $49(22.5 \%)$ \\
\hline Hospital Stay (days) & $18(13-26)$ \\
\hline ICU Stay (days) & $2(1-4)$ \\
\hdashline Mortality (30 days) & $3(1.4 \%)$ \\
Mortality (one year) & $11(5 \%)$ \\
\hline Data are median (IQR) or $\mathrm{n}(\%)$. &
\end{tabular}

of several risk factors during orthotopic liver transplant (OLT) could lead to increased EAD severity (13). Multivariate regression analysis has shown that age, donor graft steatosis, and ICU stay are factors that lead to EAD (7). The MELD and Child-Pugh scores were found to be graft dysfunction-related variables that highlight the relevance of recipients' illness severity for EAD predisposition $(5,14)$.

Brea-Gomez et al found that the onset of EAD after OLT (defined according to the criteria of Olthoff et al (5) and MEAF score) is initiated by several factors: regarding donor factors, a younger age; among the recipient characteristics, younger patients, with lower body mass indexes and hepatic impairment. Prolonged organ total ischemia time was the most significant transplant factor predisposing to EAD development (1) $E A D$ is associated, in turn, with increased recipient susceptibility to sepsis, (15) longer intensive care unit (ICU) and hospital stays, $(5,16,17)$ graft loss, (18) and greater morbidity and mortality $(14,19,20)$. In many different studies, EAD has been demonstrated to be an

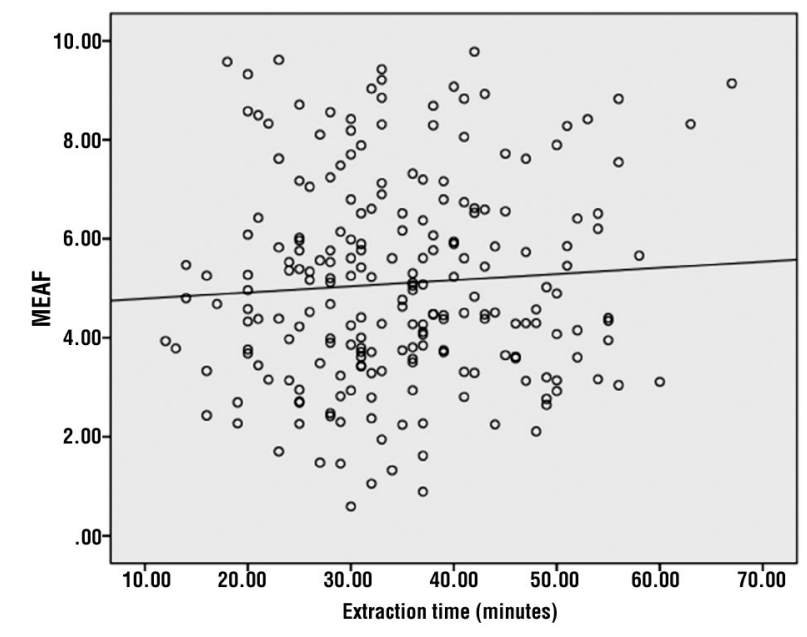

Figure 2 - Scatterplot showing association between donor liver extraction time and MEAF score

independent risk factor for graft loss and patient death $(17,18,19,21)$.

Gomez et al concluded that MEAF score and Olthoff criteria are both helpful methods for the identification of EAD. They claimed that with the latter, patients at risk could be selected more accurately, but its calculation cannot be done before the seventh day after OLT, unlike MEAF score, which is available on the third day (1). The main benefit of the MEAF score is its continuous nature, which enables patients to be categorised according to the severity of EAD rather than simply being classified into two groups (7). Jochmans et al reported that MEAF is an independent predictor of survival not only for 3 months but also for 6 and 12 months of transplantation. In addition, they showed that the MEAF core more precisely predicts transplant failure than EAD, whether viewed as a

Table 5 - Univariate analysis for the MEAF score

\begin{tabular}{lccccc}
\hline Variable & Coefficient & SE & 95\% confidence interval & Test statistic & P Value \\
\hline Donor liver extraction time (min) & 0.215 & 2.828 & $0.075-0.498$ & 1.986 & $0.041^{*}$ \\
\hline Cold Ischemia Time CIT (min) & 0.397 & 0.532 & $0.142-0.726$ & 2.608 & $0.008^{*}$ \\
\hline Warm Ischemia Time WIT (min) & 0.131 & 0.011 & $0.103-1.459$ & 1.856 & 0.065 \\
\hline Operative Time (min) & 0.183 & 4.523 & $0.083-1.105$ & 0.861 & 0.412 \\
\hline Donor sodium level (mmol/L) & 0.094 & 0.73 & $0.027-0.234$ & 0.937 & 0.362 \\
\hline
\end{tabular}

Table 6 - Multivariate linear regression model for the MEAF score

\begin{tabular}{lccccc}
\hline Variable & Coefficient & SE & 95\% confidence interval & Test statistic & P Value \\
\hline Donor liver extraction time $(\mathrm{min})$ & 0.362 & 0.62 & $0.136-0.563$ & 2.023 & $0.044^{*}$ \\
\hline Cold Ischemia Time CIT $(\mathrm{min})$ & 0.518 & 8.63 & $0.239-0.761$ & 2.561 & $0.011^{*}$ \\
\hline
\end{tabular}


stand-alone variable or coupled to other independent predictors (6). MEAF is a more reliable transplant failure predictor than the EAD classification that is widely used. MEAF offers additional, granulated data as a continuous score ranking graft dysfunction that could be used both clinically and as a surrogate endpoint of transplant survival in clinical trials (6). They had a median MEAF score of 4 (3-6), they also found out that a MEAF score of $\leq 4$ correlated with graft survival of $92 \%, 80 \%$ for a MEAF score between 6 and 8 and $62 \%$ for scores more than 8 (6). The median MEAF score in our group of patients is (4.82 [3.61-6.51]) which is similar to the one previously reported in the same study.

For a number of different factors, there is established variability in extraction time, and cooling of the liver graft is thought not to be optimal during the time between aortic cross-clamp and extraction. Adequate liver cooling is still not optimal until the organ is taken out of the body cavity, immersed in ice slush, and the portal vein is flushed on the back table (8). So, in other words, prolonged extraction time is effectively another added warm ischemic injury, with the organ rewarming in situ (12). In a pig model, studying temperature variations during organ harvesting, hepatic core temperature dropped below $5^{\circ} \mathrm{C}$ after 75 to 100 minutes (22). It took 3 hours so that a stable temperature of $1^{\circ} \mathrm{C}$ could be reached after start of the cold flush into donor body, when the liver had been harvested and stored in ice (22). Recently, a similar effect of donor extraction time has been reported on delayed graft function in kidney transplantation. For each additional 5 minutes of kidney donor extraction time over 60 minutes, there was an increase in the odds ratio for delayed graft function (12) In our study of 218 liver transplant recipients, the donor extraction time had a major effect on early post-transplant graft function, as measured by the MEAF score in univariate analysis. This has been confirmed in a multivariable regression analysis. This effect was independent of well-established risk factors for graft dysfunction, such as CIT, WIT and donor serum sodium.

Median donor extraction time reported by Adelmann et al was 40 minutes (32-51) (8). Similarly, donor hepatectomy time in the Eurotransplant cohort study was 41 minutes (32-52) (23). Median extraction time in our set of patients is a bit less, 33 minutes (1267) with longer donor hepatectomy time in DCD Grafts 41 minutes (17 to 63 ) than DBD livers 32 minutes (12 to $67),(P<0.001)$ potentially showing additional risk factor for DCD grafts. Most probably, this is because in DCD, unlike in DBD, the whole process of hepatic dissection is carried out after aortic cross clamp and so longer donor hepatectomy time is not surprising. Adelmann et al have shown that interferences at the donor level could affect post-transplant outcome. Interventions to decrease donor extraction time, such as increasing awareness for the importance of short donor extraction times and surgical training, could lead to enhanced organ quality and post-transplant function (8).

We acknowledge some limitations in our study. This analysis was performed retrospectively, although the data were all recorded prospectively. It shows a single centre experience and hence, for accurate applicability of such results to wider patient populations larger multi-centre studies should be conducted, especially to categorize the impact of donor procurement time within the context of other marginal donor criteria. Some operative data such as intra-operative blood loss and transfusion requirements, which might affect early post-transplant outcome, were missing and accordingly were not included in our analysis.

\section{CONCLUSION}

In summary, our results did show an independent effect of donor extraction time on early graft function after liver transplantation. Awareness and attempts to shorten donor extraction time during liver procurement and better synchronization between retrieval teams could decrease the incidence of early allograft dysfunction and hence boost graft survival in deceased liver transplantation.

\section{Conflicts of interest}

The authors declare no conflicts of interest.

\section{Financial disclosure statement}

The authors declare no funding was received for this study.

\section{Ethical statement}

All authors verify that the presented research does not involve the use of material from executed prisoners or material from recipients of organs or tissues of executed prisoners. This study was carried out as a service evaluation. Research consents signed by all patients.

\section{Authorship}

Mohamed Ghazaly participated in research design, 
participated in the performance of the research, did data analysis, and participated in the writing of the paper, approval of the final draft to be published.

Veena Surendrakumar participated in the performance of the research, participated in data analysis, approval of the final draft to be published.

Navneet Tiwari participated in the performance of the research, and participated in data analysis, revision of scientific content, approval of the final draft to be published.

Pulkit Sethi participated in the performance of the research, revision of scientific content, approval of the final draft to be published.

\section{REFERENCES}

1. Brea-Gómez E, Villar-Quintana R, Plata-Illescas C, Zambudio-Carroll N, Lopez-Garrido MA, Nogueras-Lopez F, et al. Analysis of the Predictive Ability for Graft Loss and Mortality of Two Criteria for Early Allograft Dysfunction After Liver Transplantation. Transplant Proc. 2018;50(2):605-609.

2. Ali JM, Davies SE, Brais RJ, Randle LV, Klinck JR, Allison ME D, et al. Analysis of ischemia/reperfusion injury in time-zero biopsies predicts liver allograft outcomes. Liver Transpl. 2015;21(4):487-99

3. Feng S, Goodrich NP, Bragg-Gresham JL, Dykstra DM, Punch JD, DebRoy MA, et al. Characteristics associated with liver graft failure: the concept of a donor risk index. Am J Transplant. 2006; 6(4):783-90.

4. Rana A, Hardy MA, Halazun KJ, D C Woodland, Ratner LE, Samstein $B$, et al. Survival outcomes following liver transplantation (SOFT) score: a novel method to predict patient survival following liver transplantation. Am J Transplant. 2008; 8(12):2537-46.

5. Olthoff KM, Kulik L, Samstein B, Kaminski M, Abecassis M, Emond $J$, et al. Validation of a current definition of early allograft dysfunction in liver transplant recipients and analysis of risk factors. Liver Transpl. 2010;16(8):943-9.

6. Jochmans I, Fieuws S, Monbaliu D, Pirenne J. "Model for Early Allograft Function" Outperforms "Early Allograft Dysfunction" as a Predictor of Transplant Survival. Transplantation. 2017; 101(8):e258-e264.

7. Pareja E, Cortes M, Hervás D, Mir J, Valdivieso A, Castell JV, et al. A score model for the continuous grading of early allograft dysfunction severity. Liver Transpl. 2015;21(1):38-46. Epub 2014 Nov 24.

8. Adelmann D, Roll GR, Kothari R, Syed S, Burdine LJ, Tavakol M, et al. The Impact of Deceased Donor Liver Extraction Time on Early Allograft Function in Adult Liver Transplant Recipients. Transplantation. 2018:102(11): e466-e471.

9. Gillooly JF, Brown JH, West GB, Savage VM, Charnov EL. Effects of size and temperature on metabolic rate. Science. 2001;293(5538): 2248-51.

10. Hertl M, Howard TK, Lowell JA, Shenoy S, Robert P, Harvey C, et al. Changes in liver core temperature during preservation and rewarming in human and porcine liver allografts. Liver Transpl Surg. 1996;2(2):111-7.

11. Villa R, Fondevila C, Erill I, Guimerà A, Bombuy E, Gómez-Suárez C, et al. Real-time direct measurement of human liver allograft temperature from recovery to transplantation. Transplantation. 2006;81(3):483-6.

12. Osband AJ, James NT, Segev DL. Extraction time of kidneys from deceased donors and impact on outcomes. Am J Transplant. 2016 Feb;16(2):700-3. Epub 2015 Sep 28.

13. Pokorny $H$, Langer F, Herkner $H$, Schernberger R, Plochl W, Soliman $T$, et al. Influence of cumulative number of marginal donor criteria on primary organ dysfunction in liver recipients. Clin Transplant. 2005; 19(4):532-6.

14. Croome KP, Wall W, Quan D, Vangala S, McAlister V, Marotta P, et al. Evaluation of the updated definition of early allograft dysfunction in donation after brain death and donation after cardiac death liver allografts. Hepatobiliary Pancreat Dis Int. 2012:11(4):372-6.

15. Howard TK, Klintmalm GB, Cofer JB, Husberg BS, Goldstein RM, Gonwa TA. The influence of preservation injury on rejection in the hepatic transplant recipient. Transplantation. 1990;49(1):103-7.

16. Deschenes M, Belle SH, Krom RA, Zetterman RK, Lake JR. Early allograft dysfunction after liver transplantation: a definition and predictors of outcome. National Institute of Diabetes and Digestive and Kidney Diseases Liver Transplantation Database. Transplantation. 1998;66(3):302-10.

17. Croome KP, Hernandez-Alejandro R, Chandok N. Early allograft dysfunction is associated with excess resource utilization after liver transplantation. Transplant Proc. ;45(1):259-64.

18. Salvalaggio P, Afonso RC, Felga G, Ferraz-Neto BH. A proposal to grade the severity of early allograft dysfunction after liver transplantation. Einstein (Sao Paulo). 2013;11(1):23-31. En, Portuguese

19. Pokorny H, Gruenberger T, Soliman T, Rockenschaub S, Langle F, Steininger R. Organ survival after primary dysfunction of liver grafts in clinical orthotopic liver transplantation. Transpl Int 2000;13(suppl 1):S154-S157.

20. Briceno J, Ciria R. Early graft dysfunction after liver transplantation. Transplant Proc. 2010;42(2):631-3.

21. Briceno J, Ciria R, de la Mata M, Rufian S, Lopez-Cillero P. Prediction of graft dysfunction based on extended criteria donors in the Model for End-Stage Liver Disease score era. Transplantation. 2010;90(5):530-9.

22. Hertl M, Howard TK, Lowell JA, Shenoy S, Robert P, Harvey C, et al. Changes in liver core temperature during preservation and rewarming in human and porcine liver allografts. Liver Transpl Surg. 1996;2(2):111-7.

23. Jochmans I, Steffen F, Ineke T, Undine S, Pirenne J. The Impact of Hepatectomy Time of the Liver Graft on Post-transplant Outcome. A Eurotransplant Cohort Study. Ann Surg. 2019;269(4):712-717. 